\title{
Impaired insulin-induced site-specific phosphorylation of TBC1 domain family, member 4 (TBC1D4) in skeletal muscle of type 2 diabetes patients is restored by endurance exercise-training
}

\author{
B. F. Vind • C. Pehmøller • J. T. Treebak • J. B. Birk • \\ M. Hey-Mogensen • H. Beck-Nielsen • J. R. Zierath • \\ J. F. P. Wojtaszewski • K. Højlund
}

Received: 13 May 2010 /Accepted: 3 September 2010 /Published online: 13 October 2010

(C) Springer-Verlag 2010

\begin{abstract}
Aims/hypothesis Insulin-mediated glucose disposal rates $\left(R_{\mathrm{d}}\right)$ are reduced in type 2 diabetic patients, a process in which intrinsic signalling defects are thought to be involved. Phosphorylation of TBC1 domain family, member 4 (TBC1D4) is at present the most distal insulin receptor signalling event linked to glucose transport. In this study, we examined insulin action on site-specific phosphorylation of TBC1D4 and the effect of exercise training
\end{abstract}

B. F. Vind and C. Pehmøller contributed equally to this study.

Electronic supplementary material The online version of this article (doi:10.1007/s00125-010-1924-4) contains supplementary material, which is available to authorised users.

B. F. Vind $\cdot$ H. Beck-Nielsen $\cdot$ K. Højlund $(\bowtie)$

Diabetes Research Center, Department of Endocrinology,

Odense University Hospital,

Kløvervænget 6, 4,

5000 Odense, Denmark

e-mail: k.hojlund@dadlnet.dk

C. Pehmøller · J. T. Treebak ·J. B. Birk · J. F. P. Wojtaszewski

Molecular Physiology Group, Copenhagen Muscle Research

Centre, Department of Exercise and Sport Sciences,

University of Copenhagen,

Copenhagen, Denmark

M. Hey-Mogensen

Institute of Sports Science and Clinical Biomechanics,

University of Southern Denmark,

Odense, Denmark

\section{J. R. Zierath}

Section for Integrative Physiology, Department of Molecular

Medicine and Surgery, Karolinska Institutet,

Stockholm, Sweden on insulin action and signalling to TBC1D4 in skeletal muscle from type 2 diabetic patients.

Methods During a $3 \mathrm{~h}$ euglycaemic-hyperinsulinaemic $\left(80 \mathrm{mU} \mathrm{min}^{-1} \mathrm{~m}^{-2}\right)$ clamp, we obtained M. vastus lateralis biopsies from 13 obese type 2 diabetic and 13 obese, nondiabetic control individuals before and after 10 weeks of endurance exercise-training.

Results Before training, reductions in insulin-stimulated $R_{\mathrm{d}}$, together with impaired insulin-stimulated glycogen synthase fractional velocity, Akt $\mathrm{Thr}^{308}$ phosphorylation and phosphorylation of TBC1D4 at $\mathrm{Ser}^{318}, \mathrm{Ser}^{588}$ and $\mathrm{Ser}^{751}$ were observed in skeletal muscle from diabetic patients. Interestingly, exercise-training normalised insulin-induced TBC1D4 phosphorylation in diabetic patients. This happened independently of increased TBC1D4 protein content, but exercise-training did not normalise Akt phosphorylation in diabetic patients. In both groups, training-induced improvements in insulin-stimulated $R_{\mathrm{d}}(\sim 20 \%)$ were associated with increased muscle protein content of Akt, TBC1D4, $\alpha 2$-AMP-activated kinase (AMPK), glycogen synthase, hexokinase II and GLUT4 (20-75\%).

Conclusions/interpretation Impaired insulin-induced sitespecific TBC1D4 phosphorylation may contribute to skeletal muscle insulin resistance in type 2 diabetes. The mechanisms by which exercise-training improves insulin sensitivity in type 2 diabetes may involve augmented signalling of TBC1D4 and increased skeletal muscle content of key insulin signalling and effector proteins, e.g., Akt, TBC1D4, AMPK, glycogen synthase, GLUT4 and hexokinase II.

Keywords Akt · Exercise-training · Glycogen synthase · Insulin signalling · TBC1D4 - Type 2 diabetes 


$\begin{array}{ll}\text { Abbreviations } \\ \text { AMPK } & \text { AMP-activated protein kinase } \\ \% \mathrm{FV} & \text { Per cent fractional velocity } \\ \mathrm{HGP} & \text { Hepatic glucose production } \\ \text { \%I-form } & \begin{array}{l}\text { Glucose 6-phosphate-independent glycogen } \\ \text { synthase activity }\end{array} \\ & \begin{array}{l}\text { Phospho (Ser/Thr) Akt substrate } \\ \text { PAS }\end{array} \\ R_{\mathrm{d}} & \text { Glucose disposal rates } \\ \text { TBC1D4 } & \text { TBC1 domain family member 4 } \\ \dot{V} \mathrm{O}_{2 \text { peak }} & \text { Peak volume of oxygen utilisation }\end{array}$

\section{Introduction}

Impaired insulin-stimulated glucose disposal in skeletal muscle is a prominent feature of insulin resistance and type 2 diabetes. Defects in insulin signalling along pathways controlling glucose uptake and storage may be either a primary or secondary cause further exacerbating insulin resistance [1]. To increase our current understanding of the molecular mechanisms underlying insulin resistance, further elucidation of these pathways is essential.

Akt is a critical node in the insulin signalling pathway [2], serving as a point of divergence for downstream signalling to glucose transport through $\mathrm{TBC} 1$ domain family, member 4 (TBC1D4, also known as AS160) and TBC1 domain family, member 1 (TBC1D1), as well as to glycogen synthesis through glycogen synthase kinase 3 and glycogen synthase. Activation of Akt requires phosphorylation at $\mathrm{Thr}^{308}$ by 3-phosphoinositide-dependent protein kinase- 1 and at $\operatorname{Ser}^{473}$ by the mammalian target of rapamycin-Rictor complex [2]. TBC1D4 is an Akt substrate thought to be involved in the regulation of glucose uptake in skeletal muscle and adipocytes [3-5]. TBC1D4 contains two phospho-tyrosine binding domains, a Rab GTPase-activating protein domain and at least nine phosphorylation sites $\left(\mathrm{Ser}^{318}, \mathrm{Ser}^{341}, \mathrm{Thr}^{568}, \mathrm{Ser}^{570}, \mathrm{Ser}^{588}\right.$, $\mathrm{Thr}^{642}, \mathrm{Ser}^{666}, \mathrm{Ser}^{704}$ and $\mathrm{Ser}^{751}$ ) [4, 6, 7]. Under basal conditions, the GTPase-activating protein domain of TBC1D4 is proposed to retain Rab proteins in an inactive, GDP-bound form that prevents GLUT4 trafficking and thus glucose uptake via this glucose transporter. Upon phosphorylation of one or more of the described sites, GTPase activity is thought to be suppressed, perhaps through binding of 14-3-3 protein [8]. As a result, Rab proteins become loaded with GTP, subsequently leading to GLUT4 mobilisation and influx of glucose. Muscle contraction and insulin stimulate GLUT4-mediated glucose transport in skeletal muscle in an additive manner, which suggests distinct signalling pathways [9]. However, acute exercise and exercise-training enhance subsequent insulin action on glucose transport $[10,11]$, and since muscle contraction and insulin lead to TBC1D4 phosphorylation [12, 13], TBC1D4 is potentially a point of convergence for exercise- and insulin-induced signalling to glucose uptake in human skeletal muscle $[9,11,12,14]$.

Impaired insulin activation of glycogen synthase is a consistent feature of type 2 diabetes and other insulinresistant conditions [15-19]. Some, but not all [15, 20-24] studies have shown reduced insulin-mediated phosphorylation of Akt at $\mathrm{Thr}^{308}[18,24-26]$ or $\mathrm{Ser}^{473}$ [26-28] and/or TBC1D4 phosphorylation $[25,26]$ in muscle of insulinresistant individuals with and without type 2 diabetes. However, previous studies of TBC1D4 phosphorylation in insulin-resistant human muscle have used the antiphospho (Ser/Thr) Akt substrate (PAS) antibody [20, 24 26], which is believed to primarily detect $\mathrm{Thr}^{642}$ phosphorylation $[3,6]$. It remains to be determined whether insulin-mediated TBC1D4 phosphorylation at specific sites is impaired in skeletal muscle of patients with type 2 diabetes.

Exercise-training is a cornerstone in prevention and treatment of type 2 diabetes $[29,30]$ because it, among other strategies, enhances insulin sensitivity [31]. However, the mechanisms underlying the beneficial effects of exercise-training are incompletely understood. Endurance and strength exercise-training induces chronic adaptations that include increased content of key signalling proteins mediating insulin-stimulated glucose metabolism, such as insulin receptor, Akt, glycogen synthase, GLUT4 and hexokinase II [11, 31-33]. Enhanced TBC1D4 protein levels have also been reported after exercise-training in skeletal muscle of young healthy individuals [11]. This effect on protein production fully accounted for the observed enhanced PAS phosphorylation. However, TBC1D4 is a multi-protein kinase substrate and is phosphorylated on residues other than that recognised by the PAS antibody. Thus, the hypothesis of whether exercise-training improves TBC1D4 phosphorylation in general or in a site-specific manner and whether this can be accounted for by changes in TBC1D4 protein levels remains to be tested.

The present study thus sought: (1) to investigate whether type 2 diabetes is associated with abnormalities in insulininduced site-specific TBC1D4 phosphorylation in skeletal muscle; and (2) to examine the effect of endurance exercise-training on TBC1D4 and other key insulin signalling events in well-matched obese individuals with and without type 2 diabetes.

\section{Methods}

Participants Obese male type 2 diabetic patients $(n=13)$ and obese, non-diabetic male control individuals $(n=13)$ 
matched according to age, BMI and habitual physical activity level participated in the study (Table 1). Type 2 diabetic patients were treated either by diet alone $(n=2)$ or by diet in combination with sulfonylurea $(n=1)$, metformin $(n=6)$ or both $(n=4)$; they were also receiving lipidlowering $(n=6)$ and/or antihypertensive $(n=7)$ medication. The patients were GAD65-antibody negative and without signs of diabetic micro- or macrovascular complications. The control individuals had normal glucose tolerance, normal fasting glucose, no family history of diabetes and were not taking medication. All participants had normal results on blood tests screening for hepatic and renal function, and no cardiovascular disease. Informed consent was obtained from all participants before participation. The study was approved by the Local Ethics Committee and was performed in accordance with the Helsinki Declaration. One type 2 diabetic patient did not complete the study due to health problems unrelated to the training programme. Two control individuals were excluded due to non-compliance with the training programme. Pre-training data from these three participants were included in the analyses.

Training programme Exercise tests were performed before and after training to determine peak volume of oxygen utilisation $\left(\dot{V} \mathrm{O}_{2 \text { peak }}\right)$ as described [34] (ESM, Exercise tests). Participants underwent 10 weeks of aerobic training as described [34, 35]. In brief, the exercise-training programme consisted of cycling on stationary bikes with four to five sessions of 20 to $35 \mathrm{~min}$ per week at an average intensity of $\sim 65 \%$ of $\dot{V} \mathrm{O}_{2 \text { peak }}$, see Electronic supplementary material (ESM, Training programme). Diabetic patients continued their medication throughout the training period, except for one, who discontinued his glucose-lowering treatment after 6 weeks.
Euglycaemic-hyperinsulinaemic clamp and muscle biopsies At 1 to 2 weeks prior to the training programme and again at around $48 \mathrm{~h}$ after the last exercise bout, participants underwent a euglycaemic-hyperinsulinaemic clamp $(3 \mathrm{~h}$ of insulin infusion at $80 \mathrm{mUmin}^{-1} \mathrm{~m}^{-2}$ ) with tracer glucose to assess total glucose disposal rates $\left(R_{\mathrm{d}}\right)$, hepatic glucose production (HGP), glycolytic flux and rates of glucose storage as described in ESM (Euglycaemic-hyperinsulinaemic clamp). Plasma glucose levels at 5.0 to $5.5 \mathrm{mmol} / \mathrm{l}$ and high physiological hyperinsulinaemia at $\sim 900 \mathrm{pmol} / 1$ were obtained in all groups during the insulin-stimulated periods. In diabetic patients, all drugs were withdrawn 1 week prior to the clamp studies and then resumed. Skeletal muscle biopsies were obtained from the vastus lateralis muscle before and after insulin, and homogenates and lysates were prepared as described in ESM (Euglycaemic-hyperinsulinaemic clamp).

Glycogen synthase activity Muscle glycogen synthase activity was measured in the presence of $8.0,0.17$ or $0.02 \mathrm{mmol} / 1$ glucose 6-phosphate as described [19] and given as total glycogen synthase activity, glucose 6phosphate-independent glycogen synthase activity (\%Iform) and per cent fractional velocity (\%FV) (see ESM, Glycogen synthase activity).

SDS-PAGE and western blotting Western blot analyses were performed as described [36] (ESM, SDS-PAGE and western blotting). Membranes used for detection of phosphorylated Akt, TBC1D4 or AMP-activated protein kinase (AMPK) were stripped as previously described [12] and reprobed for the corresponding protein using an antibody recognising the protein independently of phosphorylation. A list of the antibodies used is given in ESM (Antibodies).
Table 1 Anthropometric and metabolic characteristics before and after 10 weeks endurance training

Data are means \pm SEM

${ }^{\text {a }} n=10$ type 2 diabetic patients post-training

${ }^{*} p<0.05,{ }^{* *} p<0.01$ and

$* * * p<0.001$ vs CON; ${ }^{\dagger} p<0.05$

and ${ }^{\dagger \dagger} p<0.001$ vs pre-training

T2D, type 2 diabetic patients

\begin{tabular}{|c|c|c|c|c|}
\hline \multirow[t]{2}{*}{ Characteristic } & \multicolumn{2}{|l|}{ Pre-training } & \multicolumn{2}{|l|}{ Post-training } \\
\hline & Control & $\mathrm{T} 2 \mathrm{D}$ & Control & $\mathrm{T} 2 \mathrm{D}$ \\
\hline$n$ & 13 & 13 & 11 & 12 \\
\hline Age (years) & $52.7 \pm 1.6$ & $52.8 \pm 1.3$ & - & - \\
\hline BMI $\left(\mathrm{kg} / \mathrm{m}^{2}\right)$ & $33.0 \pm 0.7$ & $33.5 \pm 0.1$ & $32.7 \pm 0.8^{\dagger \dagger \dagger}$ & $33.4 \pm 0.1$ \\
\hline Lean body mass (kg) & $74.7 \pm 2.1$ & $72.7 \pm 1.9$ & $75.9 \pm 2.2$ & $74.3 \pm 1.7$ \\
\hline Fat mass $(\mathrm{kg})$ & $35.7 \pm 2.5$ & $34.9 \pm 2.1$ & $32.9 \pm 2.5$ & $33.7 \pm 1.9$ \\
\hline$\dot{V} \mathrm{O}_{2 \text { peak }}\left(\mathrm{ml} \mathrm{min}^{-1} \mathrm{~kg}^{-1}\right)^{\mathrm{a}}$ & $27.8 \pm 1.5$ & $26.7 \pm 0.9$ & $34.6 \pm 2.2^{\dagger \dagger}$ & $29.8 \pm 1.2^{\dagger \dagger \dagger}$ \\
\hline Fasting plasma glucose $(\mathrm{mmol} / \mathrm{l})$ & $5.8 \pm 0.1$ & $9.4 \pm 0.5^{* * *}$ & $5.5 \pm 0.1$ & $9.2 \pm 0.5^{* * *}$ \\
\hline Fasting serum insulin (pmol/l) & $64 \pm 7$ & $82 \pm 11$ & $50 \pm 4^{\dagger}$ & $78.0 \pm 13$ \\
\hline Fasting serum C-peptide (pmol/l) & $945 \pm 65$ & $1268 \pm 113^{*}$ & $804 \pm 57^{\dagger}$ & $1243 \pm 138^{* * *}$ \\
\hline $\mathrm{HbA}_{1 \mathrm{c}}(\%)$ & $5.2 \pm 0.1$ & $7.2 \pm 0.3^{* * *}$ & $5.3 \pm 0.1$ & $7.0 \pm 0.3^{* * *}$ \\
\hline Fasting plasma cholesterol (mmol/l) & $5.5 \pm 0.2$ & $5.0 \pm 0.2$ & $5.2 \pm 0.2$ & $4.8 \pm 0.2$ \\
\hline Fasting plasma triacylglycerol $(\mathrm{mmol} / \mathrm{l})$ & $1.69 \pm 0.17$ & $2.37 \pm 0.32$ & $1.51 \pm 0.17$ & $2.38 \pm 0.31$ \\
\hline Diabetes duration (years) & - & $3.7 \pm 0.8$ & - & - \\
\hline
\end{tabular}


Statistics Data are presented as means \pm SEM. Data analysis was performed using four separate two-way ANOVA with repeated measures to explore the effect of training (12 diabetic patients, 11 controls) in each of the study groups and to explore differences ( \pm insulin) between the two study groups before (13 diabetic patients, 13 controls) and after (12 diabetic patients, 11 controls) training. Statistical analyses were performed by SigmaStat version 3.5 (Systat Software, San Jose, CA, USA). Significant interactions were analysed by Tukey's post hoc test. A value of $p<0.05$ was accepted as statistically significant.

\section{Results}

Metabolic characteristics At baseline, $\mathrm{HbA}_{1 \mathrm{c}}$, fasting levels of plasma glucose, NEFA and serum C-peptide were significantly elevated in diabetic patients compared with controls (Tables 1 and 2). Insulin increased $R_{\mathrm{d}}$ and suppressed HGP significantly in both groups; however, insulin-stimulated $R_{\mathrm{d}}$ in type 2 diabetic patients was $38 \%$ lower than in controls (Table 2). In parallel with this, the former had lower insulin-stimulated glucose storage (45\%) and glycolytic flux (20\%), indicating that the reduction in insulin-stimulated $R_{\mathrm{d}}$ was primarily due to impaired insulininduced glucose storage (Table 2). Muscle glycogen levels were similar between groups before and after training, but showed an approximately $30 \%$ to $40 \%$ increase in response to training in both groups (Table 2).
General adaptation to exercise $\dot{V} \mathrm{O}_{2 \text { peak }}$ and body composition were similar at baseline in the two groups (Table 1). Compliance to the training, assessed as the percentage of completed exercise sessions confirmed by heart rate monitor recordings, amounted to $97 \pm 1 \%$ in type 2 diabetic patients and controls. Training increased $\dot{V} \mathrm{O}_{2 \text { peak }}$ and insulin-stimulated $R_{\mathrm{d}}$ in both groups (Tables 1 and 2), also when related to lean body mass (data not shown) $(p<0.01)$. In the controls, training increased insulin-stimulated glucose storage and glycolytic flux, whereas it reduced BMI, and serum insulin and C-peptide (Tables 1 and 2). In type 2 diabetic patients, insulin-mediated glycolytic flux $(p=$ $0.064)$ and HGP $(p=0.052)$ tended to increase after training, whereas glucose storage, BMI, serum insulin and C-peptide were unchanged.

TBC1D4 protein content and phosphorylation TBC1D4 protein levels did not differ between type 2 diabetic and control individuals either before or after training. Training increased TBC1D4 protein by around $20 \%$ in both groups (Fig. 1). Basal TBC1D4 phosphorylation at $\mathrm{Ser}^{318}$, $\mathrm{Ser}^{341}, \mathrm{Ser}^{588}$, $\mathrm{Thr}^{642}$ and $\mathrm{Ser}^{751}$, and PAS phosphorylation of TBC1D4 were similar in the diabetic and control groups before and after training (Fig. 1). Insulin increased TBC1D4 phosphorylation at all sites and PAS phosphorylation in both groups before, as well as after training (all $p<0.006)$. However, before training, insulinstimulated TBC1D4 phosphorylation at $\operatorname{Ser}^{318}(p<$ $0.001), \operatorname{Ser}^{588}(p=0.006)$ and $\operatorname{Ser}^{751}(p<0.001)$, as well
Table 2 Metabolic characteristics before and after 10 weeks endurance training

\footnotetext{
Values are means \pm SEM

${ }^{*} p<0.05, * * p<0.01$ and

$* * * p<0.001$ vs basal; ${ }^{\dagger} p<0.05$,

${ }^{\dagger} p<0.01$ and ${ }^{\dagger \dagger} p<0.001$ vs pretraining; ${ }^{*} p<0.05,{ }^{\star \star} p<0.01$ and

$\$ p<0.001$ vs CON

Gl., glucose; T2D, type 2

diabetic patients
}

\begin{tabular}{|c|c|c|c|c|}
\hline \multirow[t]{2}{*}{ Characteristic } & \multicolumn{2}{|l|}{ Pre-training } & \multicolumn{2}{|l|}{ Post-training } \\
\hline & Control & $\mathrm{T} 2 \mathrm{D}$ & Control & $\mathrm{T} 2 \mathrm{D}$ \\
\hline$n$ & 13 & 13 & 11 & 12 \\
\hline \multicolumn{5}{|l|}{$R_{\mathrm{d}}\left(\mathrm{mgmin}^{-1} \mathrm{~m}^{-2}\right)$} \\
\hline Basal & $84 \pm 3$ & $85 \pm 2$ & $84 \pm 1$ & $91 \pm 3^{*}$ \\
\hline Clamp & $327 \pm 22^{* * *}$ & $208 \pm 26^{\text {t+**** }}$ & $400 \pm 39^{* * *+1 \dagger}$ & $242 \pm 30^{+1+* * *+1}$ \\
\hline Gl. storage clamp $\left(\mathrm{mg} \mathrm{min}^{-1} \mathrm{~m}^{-2}\right)$ & $215 \pm 20$ & $118 \pm 19^{t+}$ & $280 \pm 35^{\dagger \dagger}$ & $133 \pm 24^{t+1}$ \\
\hline \multicolumn{5}{|l|}{ Glycolytic flux $\left(\mathrm{mg} \mathrm{min} \mathrm{m}^{-1} \mathrm{~m}^{-2}\right)$} \\
\hline Basal & $76 \pm 3$ & $73 \pm 4$ & $84 \pm 4$ & $85 \pm 5$ \\
\hline Clamp & $112 \pm 5^{* * *}$ & $90 \pm 9^{\ddagger *}$ & $120 \pm 8^{* * * \dagger}$ & $108 \pm 14$ \\
\hline \multicolumn{5}{|l|}{$\operatorname{HGP}\left(\mathrm{mgmin}^{-1} \mathrm{~m}^{-2}\right)$} \\
\hline Basal & $84 \pm 3$ & $79 \pm 3$ & $86 \pm 1$ & $85 \pm 5$ \\
\hline Clamp & $21 \pm 7^{* * *}$ & $26 \pm 3^{* * *}$ & $38 \pm 10^{* * *}$ & $35 \pm 4^{* * *}$ \\
\hline \multicolumn{5}{|l|}{ Glycogen (mg/mmol protein) } \\
\hline Basal & $6.9 \pm 0.4$ & $8.5 \pm 0.6$ & $10.2 \pm 0.5^{\dagger \dagger \dagger}$ & $11.4 \pm 0.7^{\dagger}$ \\
\hline Clamp & $7.9 \pm 0.5^{* *}$ & $8.3 \pm 0.7$ & $11.6 \pm 0.6^{* *+1 \dagger}$ & $10.9 \pm 0.9^{\dagger}$ \\
\hline \multicolumn{5}{|l|}{ NEFA (mmol/l) } \\
\hline Basal & $0.41 \pm 0.03$ & $0.52 \pm 0.04$ & $0.42 \pm 0.03$ & $0.47 \pm 0.05$ \\
\hline Clamp & $0.03 \pm 0.00^{* * *}$ & $0.07 \pm 0.01^{* * *}$ & $0.03 \pm 0.00^{* * *}$ & $0.06 \pm 0.01^{* * *}$ \\
\hline Serum insulin clamp (pmol/1) & $899 \pm 36$ & $894 \pm 43$ & $860 \pm 53$ & $891 \pm 40$ \\
\hline
\end{tabular}


a
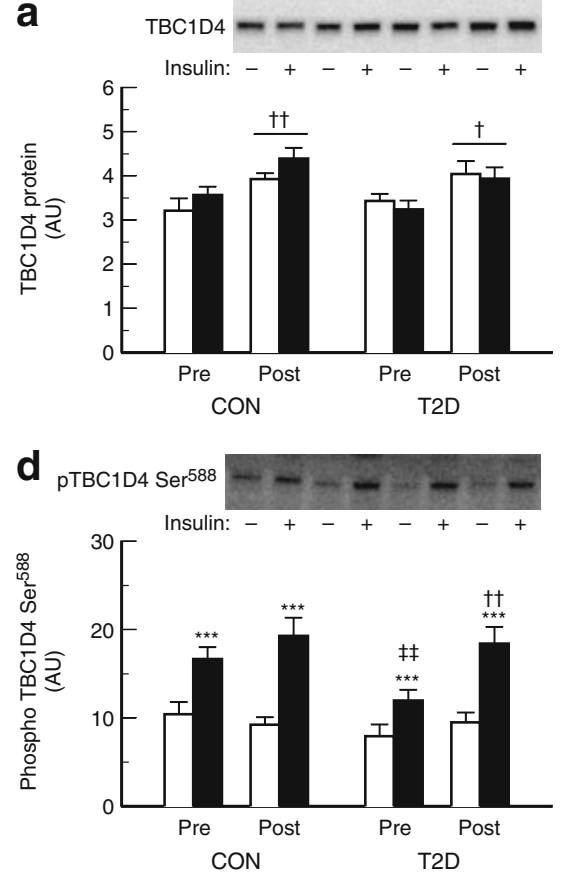
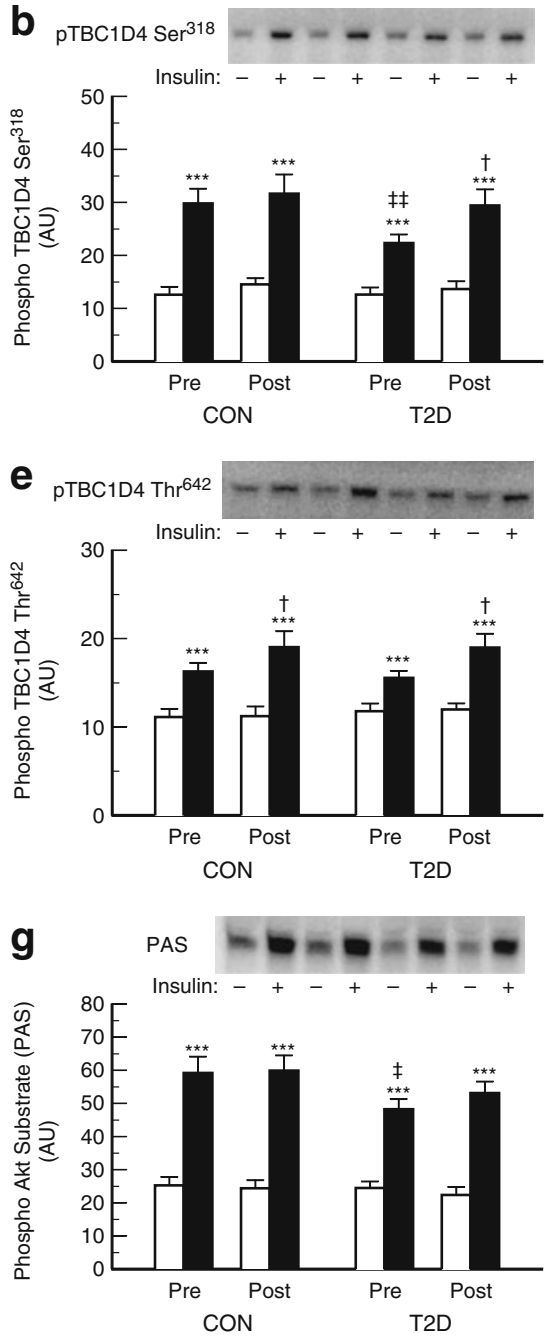
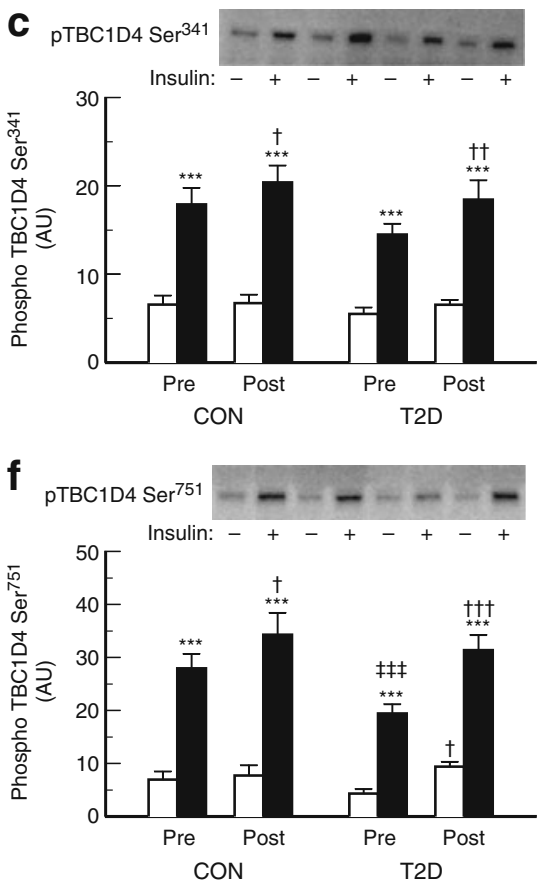

Fig. 1 Protein levels of TBC1D4 (a) and phosphorylation of $\mathrm{Ser}^{318}$ (b), $\operatorname{Ser}^{341}$ (c), $\operatorname{Ser}^{588}$ (d), $\mathrm{Thr}^{642}$ (e) and $\mathrm{Ser}^{751}$ (f). g PAS phosphorylation. Findings are shown in representative immunoblots, quantified in bar graphs as arbitrary units (AU). Measurements were performed in skeletal muscle biopsies obtained from type 2 diabetic (T2D) and control (CON) individuals during the basal (white bars)

as PAS phosphorylation $(p=0.024)$ were lower in type 2 diabetic than in control individuals (Fig. 2). These abnormalities persisted after correction for TBC1D4 protein levels except for PAS phosphorylation $(p=0.097)$ (ESM Fig. 1). In diabetic patients, exercise-training increased insulin-mediated TBC1D4 phosphorylation at $\operatorname{Ser}^{318}(\sim 30 \%, p<0.03), \operatorname{Ser}^{588}(\sim 60 \%, p<0.003)$ and $\operatorname{Ser}^{751}(\sim 60 \%, p<0.001)$. In fact, these effects fully normalised the insulin responses at these three sites compared with matched controls (Fig. 1). In both groups, training increased insulin-induced phosphorylation at $\mathrm{Ser}^{341}$ and $\mathrm{Thr}^{642}$; in controls a small increase in phosphorylation of $\mathrm{Ser}^{751}$ was also seen. After normalisation for TBC1D4 protein, the increase in $\mathrm{Ser}^{588}$ and $\mathrm{Ser}^{751}$ phosphorylation in diabetic patients remained and insulin-stimulated (black bars) steady-state periods of a $3 \mathrm{~h}$ euglycaemic-hyperinsulinaemic clamp before (Pre) and after (Post) 10 weeks of endurance training. Line above bar pairs (a), main effect of training. Data are means \pm SEM. ${ }^{* * *} p<0.001 \mathrm{vs}$ basal; ${ }^{\star} p<0.05$, ${ }^{+} p<0.01$ and ${ }^{+\dagger} p<0.001$ vs CON; ${ }^{\dagger} p<0.05,{ }^{\dagger} p<0.01$ and ${ }^{\dagger \dagger} p<$ 0.001 vs Pre

significant ( $p<0.05$ for all) (ESM Fig. 1). Thus, TBC1D4 displayed enhanced sensitivity toward activation by insulin at two phosphorylation residues after exercisetraining. After training, the defect in insulin-stimulated PAS phosphorylation of TBC1D4 in the type 2 diabetic group was no longer detectable. However, training had no significant effect on PAS phosphorylation in this group with or without correction for TBC1D4 protein. In controls, a decrease in PAS phosphorylation per TBC1D4 protein was observed after training ( $p=0.006$ for main effect) (ESM Fig. 1).

Akt protein content and phosphorylation Protein levels of Akt1 and Akt2 did not differ between groups either before or after training. Training increased Akt1 protein by $\sim 20 \%$ 
a

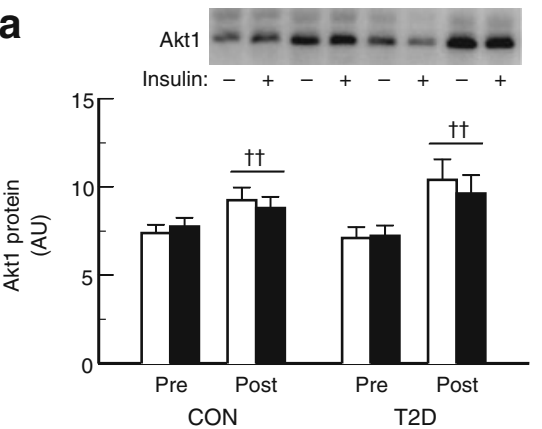

d
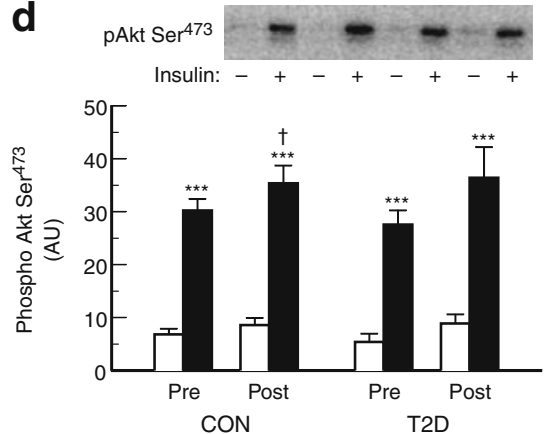

b

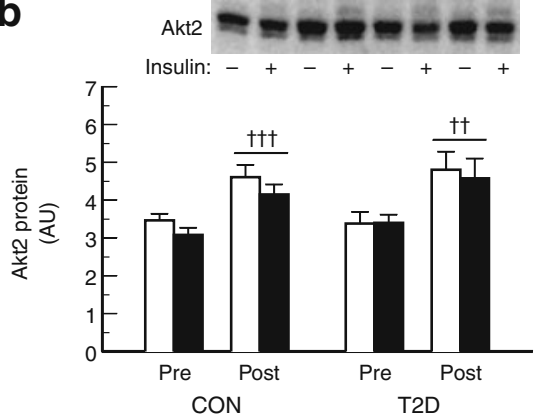

e

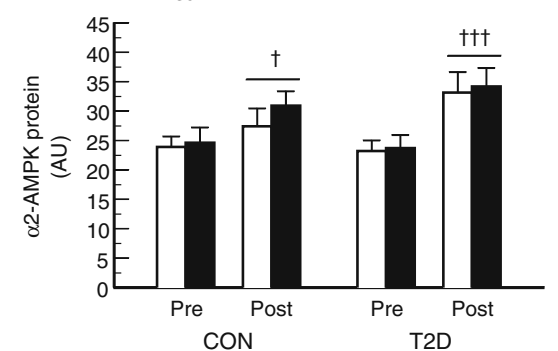

C

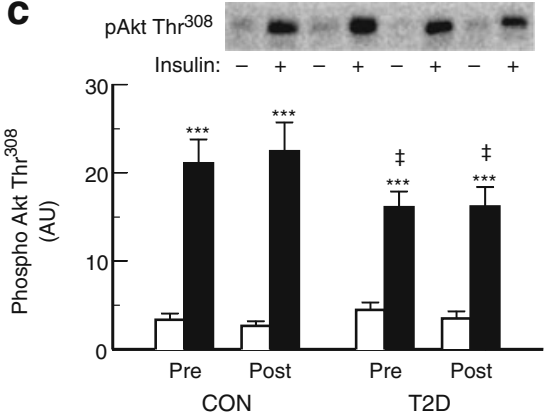

f
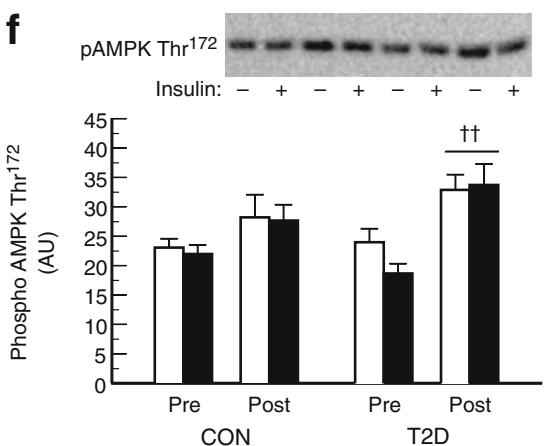

Fig. 2 Protein levels of Akt1 (a) and Akt2 (b), and phosphorylation of Akt at (c) $\mathrm{Thr}^{308}$ and (d) $\mathrm{Ser}^{473}$. e $\alpha 2-\mathrm{AMPK}$ protein levels and (f) AMPK $\operatorname{Thr}^{172}$ phosphorylation. Findings are shown in representative immunoblots, quantified in bar graphs as arbitrary units (AU).
Measurements were performed as in Fig. 1. Line above bar pairs, main effect of training. Data are means \pm SEM. $* * * p<0.001$ vs basal; ${ }^{\ddagger} p<0.05$ vs CON; ${ }^{\dagger} p<0.05,{ }^{\dagger \dagger} p<0.01$ and ${ }^{\dagger \dagger \dagger} p<0.001$ vs Pre in the control group and by $\sim 50 \%$ in the diabetic group, and Akt 2 protein by $\sim 30$ to $40 \%$ in both groups (Fig. 2). Basal Akt phosphorylation at $\mathrm{Thr}^{308}$ and $\mathrm{Ser}^{473}$ was similar in the type 2 diabetic and control group before and after training (Fig. 2). Moreover, insulin significantly increased Akt phosphorylation at $\mathrm{Thr}^{308}$ and $\mathrm{Ser}^{473}$ in both groups before, as well as after training. However, in the insulin-stimulated state, Akt Thr $^{308}$ phosphorylation was reduced in the type 2 diabetic group compared with controls before $(p<0.02)$ and after $(p<0.05)$ training, and also when corrected for changes in Akt1 or Akt2 protein (data not shown). Training did not change basal or insulin-stimulated Akt $\mathrm{Thr}^{308}$ phosphorylation in any of the groups. Insulin-induced Akt Ser $^{473}$ phosphorylation was similar between the groups. Training induced a small, but significant increase in insulinstimulated Akt Ser ${ }^{473}$ phosphorylation in the control group and a tendency to increase in the diabetic group $(p=0.082)$. These effects of training were attributable to increased levels of Akt1 or Akt2 protein, as normalisation of the phosphorylation levels to the protein content in individual samples abolished the increases in Akt Ser ${ }^{473}$ phosphorylation. In fact, the insulin-stimulated ratios of $\mathrm{Ser}^{473}$ :Akt1, $\mathrm{Ser}^{473}$ :Akt2 and $\mathrm{Thr}^{308}$ :Akt2 showed a small decrease in control individuals in response to training $(p<0.05)$, whereas in the diabetic group, training induced a decrease in the insulin-stimulated ratios of $\mathrm{Thr}^{308}$ :Akt2 and $\mathrm{Thr}^{308}$ :Akt1 $(p<0.001)$, but not of $\mathrm{Ser}^{473}: \mathrm{Akt1}$ or $\mathrm{Ser}^{473}: \mathrm{Akt} 2$ (data not shown).

AMPK protein and phosphorylation Among TBC1D4 $\mathrm{Ser}^{318}$, $\mathrm{Ser}^{588}$ and $\mathrm{Ser}^{751}$, phosphorylation of $\mathrm{Ser}^{588}$ seems to be the most important for GLUT4 translocation [4]. TBC1D4 $\operatorname{Ser}^{588}$ is also the site preferentially phosphorylated by AMPK in vitro [6]. We therefore examined whether changes in protein levels and activity of AMPK could explain the alterations in TBC1D4 phosphorylation observed in relation to type 2 diabetes and training. No differences in $\alpha 2$-AMPK protein content or AMPK Thr ${ }^{172}$ phosphorylation were observed between the groups either before or after training. Protein content of $\alpha 2$-AMPK increased in response to training in the diabetic group $(p=$ $0.001)$ and to a lesser extent in the control group $(p=0.02$ for main effect) (Fig. 2). Only in type 2 diabetic patients was a significant increase in AMPK $\mathrm{Thr}^{172}$ phosphorylation demonstrated $(p=0.003)$. This seems to be explained by the more robust increase in AMPK protein levels, because the ratio of $\mathrm{Thr}^{172}: \alpha 2-\mathrm{AMPK}$ did not show any changes between the two groups or in response to training (data not shown).

Glycogen synthase protein, activity and phosphorylation To test whether the persistent defect in insulin action 
on Akt in type 2 diabetic patients, even after training, was transmitted to one of its major down-stream effectors, we examined glycogen synthase activity and protein content. Glycogen synthase protein levels and total glycogen synthase activity were similar in the two groups before and after training (Fig. 3). Training increased glycogen synthase protein levels and total glycogen synthase activity in both groups $(p<0.001$ for all, main effect). Insulinstimulated glycogen synthase activity (\%I-form, \%FV) was reduced in the diabetic group before and after training compared with the control group ( $p<0.05$ for all). Before and after training, insulin increased glycogen synthase activity (\%I-form, $\% \mathrm{FV})$ in both groups, but insulin action on these activities of glycogen synthase was unaffected by training in both groups. Glycogen synthase site 3a phosphorylation was similar in the two groups and decreased in response to insulin in both (Fig. 3). In patients with type 2 diabetes, glycogen synthase site $2+2$ a phos- phorylation tended to increase in response to insulin ( $p=$ 0.08 ) and was higher after insulin than in controls ( $p=$ 0.025 ) before but not after training. Training increased glycogen synthase phosphorylation at site $3 \mathrm{a}$ in both groups $(p<0.05$ for main effect) and at site $2+2 \mathrm{a}$ in controls $(p<$ 0.05 for main effect), but after correction for the increase in glycogen synthase protein, no effect of training was observed (data not shown).

GLUT4 and hexokinase II protein content GLUT4 protein levels did not differ between diabetic and control individuals, whereas hexokinase II protein content was reduced in the former before and after training ( $p<0.05$ for all). Training increased GLUT4 protein levels by $\sim 20 \%$ in controls and $\sim 30 \%$ in the diabetic group (Fig. 4). Moreover, hexokinase II protein levels increased in response to training by $\sim 45 \%$ in controls and by $\sim 75 \%$ in diabetic patients (Fig. 4).
Fig. 3 Protein levels (a), total activity (b), \%FV (c), \% I-form activity (d), site $3 \mathrm{a}\left(\mathrm{Ser}^{640}\right)$ (e) and site $2+2 \mathrm{a}\left(\mathrm{Ser}^{7}+\mathrm{Ser}^{10}\right)$ phosphorylation (f) of glycogen synthase, shown as representative immunoblots and quantified in bar graphs as arbitrary units (AU). Measurements were performed as in Fig. 1. Line above bar pairs, main effect of training. Data are means \pm SEM. ${ }^{*} p<$ $0.05, * * p<0.01$ and $* * * p<$ 0.001 vs basal; ${ }^{\star} p<0.05,{ }^{\star} p<$ 0.01 and $\$+\$ p<0.001$ vs CON; ${ }^{\dagger} p<0.05$ and ${ }^{\dagger \dagger} p<0.001$ vs Pre
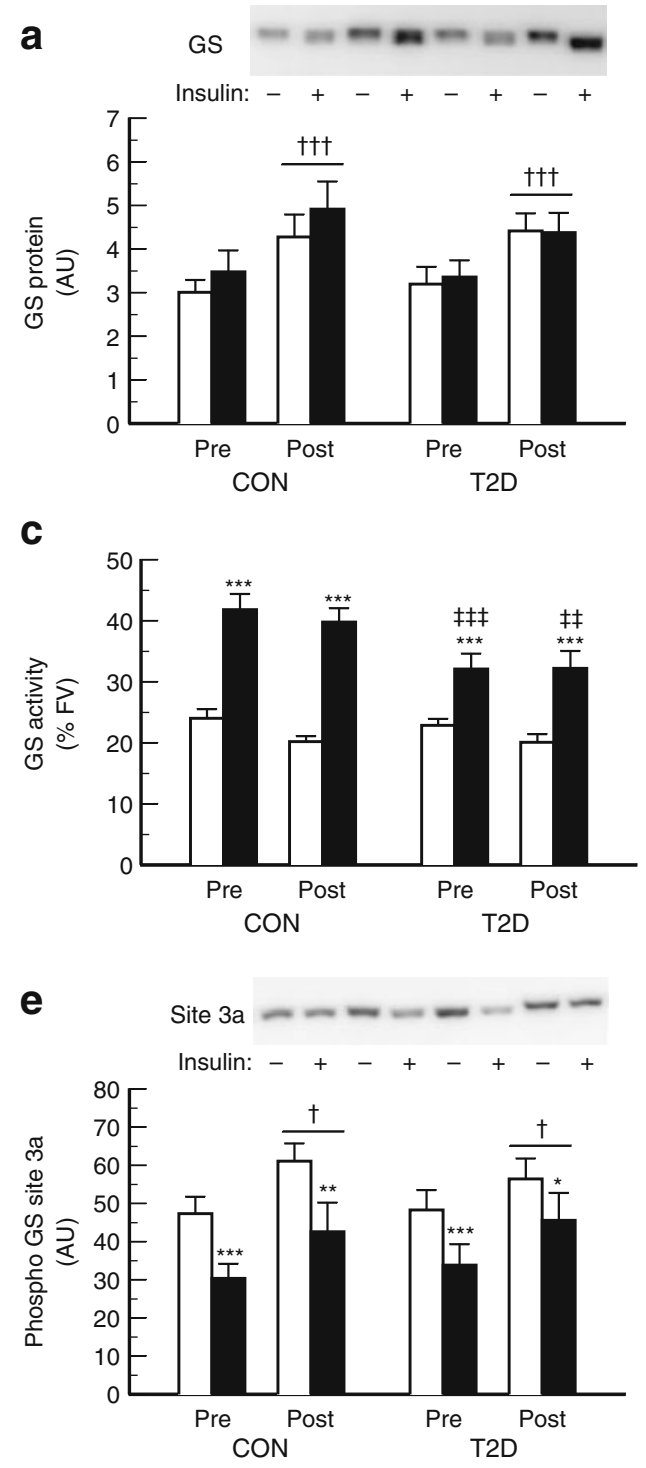

b

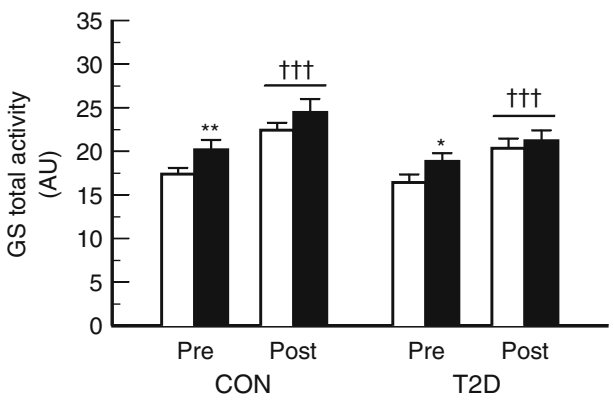

d

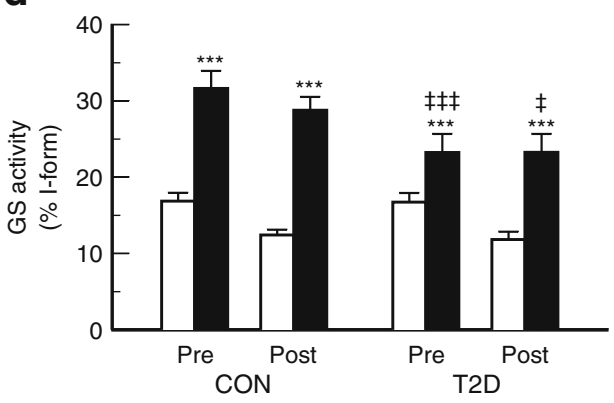

$\mathbf{f}$

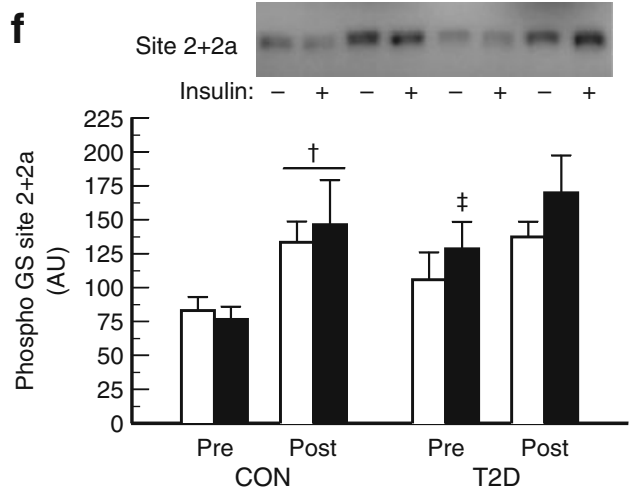



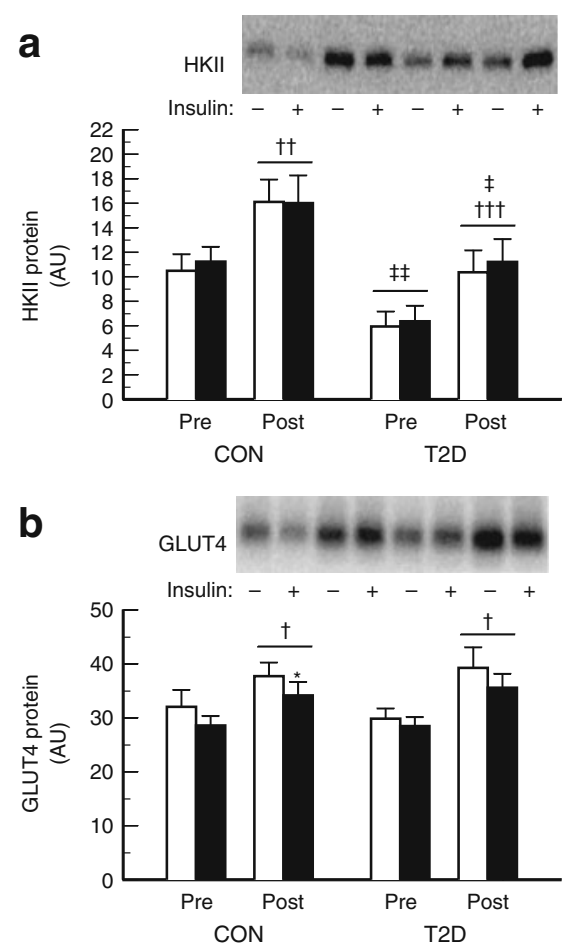

Fig. 4 Protein levels of hexokinase II (a) and GLUT4 (b), shown as representative immunoblots and quantified in bar graphs as arbitrary units (AU). Measurements were performed as in Fig. 1. Line above bar pairs, main effect of training. Data are means \pm SEM. ${ }^{*} p<0.05$ vs basal; ${ }^{\star} p<0.05$ and ${ }^{\star \star} p<0.01$ vs CON; ${ }^{\dagger} p<0.05,{ }^{\dagger \dagger} p<0.01$ and ${ }^{\dagger \dagger \dagger} p<$ 0.001 vs Pre

\section{Discussion}

Here, we evaluated insulin signalling events leading to glucose uptake and storage through Akt, TBC1D4 and glycogen synthase in skeletal muscle of type 2 diabetic patients and matched non-diabetic controls. We focused on the site-specific phosphorylation of TBC1D4 before and after 10 weeks of endurance exercise-training. In previous studies investigating TBC1D4 phosphorylation in human skeletal muscle, the anti-PAS antibody was used to assess changes in overall phosphorylation in response to various stimuli such as exercise and insulin in healthy individuals and in various states of insulin resistance [11, 13, 20, 2426, 37-39]. Recently, we used phospho-site-specific antibodies to demonstrate that insulin increases TBC1D4 phosphorylation at $\mathrm{Ser}^{318}, \mathrm{Ser}^{341}, \mathrm{Ser}^{588}, \mathrm{Thr}^{642}, \mathrm{Ser}^{666}$ and $\mathrm{Ser}^{751}$ in skeletal muscle of young, healthy individuals [12]. In the present study, we have extended these findings by demonstrating that insulin significantly increased TBC1D4 phosphorylation at the same sites in skeletal muscle from obese individuals with and without type 2 diabetes. Most importantly, we show that insulin-stimulated TBC1D4 phosphorylation at $\mathrm{Ser}^{318}, \mathrm{Ser}^{588}$ and $\mathrm{Ser}^{751}$ (but not $\mathrm{Ser}^{341}$ and $\mathrm{Thr}^{642}$ ) is impaired in untrained obese type 2 diabetic patients, compared with matched controls. Re- duced insulin-mediated TBC1D4 phosphorylation in skeletal muscle as measured by the anti-PAS antibody has been reported in non-obese type 2 diabetic patients [25], insulinresistant women with polycystic ovary syndrome [26] and healthy individuals after TNF $\alpha$ infusion [39]. Intriguingly, we found impaired insulin-mediated PAS phosphorylation of TBC1D4 but unaltered phosphorylation of $\mathrm{Thr}^{642}$ in type 2 diabetic compared with control individuals, although this site is believed to be the main site detected by the anti-PAS antibody $[3,6]$. The PAS antibody has been reported to detect TBC1D1 phosphorylation in mouse skeletal muscle [40, 41]. However, using immunopurification, we previously demonstrated that removal of TBC1D4 from human muscle lysates completely abolishes signals from the antiPAS and anti-phospho-Thr ${ }^{642}$ antibodies [12]. Thus, it is unlikely that the observed discrepancy between PAS and $\mathrm{Thr}^{642}$ phosphorylation is related to recognition of TBC1D1 in human muscle by these antibodies.

In accordance with the idea that TBC1D4 $\mathrm{Ser}^{318}, \mathrm{Ser}^{588}$ and $\mathrm{Ser}^{751}$ are downstream targets of Akt [6], and consistent with studies of non-obese type 2 diabetic patients [25] and other insulin-resistant states [18, 26], we found impaired insulin-stimulated Akt $\mathrm{Thr}^{308}$ and PAS phosphorylation in muscle of obese type 2 diabetic patients. We were previously unable to detect such differences between obese individuals with and without type 2 diabetes [15, 24]. However, in the present study, we used a twofold higher insulin infusion rate, raising insulin levels during the clamp from $\sim 400$ to $\sim 900 \mathrm{pmol} / \mathrm{l}$. Thus, stimulation with high physiological hyperinsulinaemia seems to unmask these defects in insulin-stimulated phosphorylation of Akt at $\mathrm{Thr}^{308}$ and of TBC1D4 in type 2 diabetic patients, as previously noted for Akt ex vivo [42]. Consistent with several studies, we also observed defects in insulin activation and phosphorylation of glycogen synthase [1517, 24, 43], and lower hexokinase II protein content [44] in type 2 diabetic patients. Taken together, our results suggest that, in addition to the previously described defects in insulin action on Akt and glycogen synthase, reduced insulin-mediated TBC1D4 phosphorylation at $\mathrm{Ser}^{318}, \mathrm{Ser}^{588}$ and $\mathrm{Se}^{751}$ may contribute to impaired GLUT4 translocation and glucose disposal in skeletal muscle of sedentary type 2 diabetic patients.

The effect of long-term exercise-training on signalling events involving TBC1D4 in human skeletal muscle has so far only been sparsely described. In agreement with our results, one study evaluating the effect of short-term (7 days) endurance training showed that PAS phosphorylation of TBC1D4 was unchanged in skeletal muscle of obese non-diabetic and type 2 diabetic individuals [21]. Recently, we found that 3 weeks of one-legged endurance training in young, healthy volunteers increased TBC1D4 protein levels, as well as PAS phosphorylation, both at rest and 
after insulin stimulation [11]. However, in that study the increase in TBC1D4 phosphorylation appeared to reflect a corresponding change in TBC1D4 protein content, consistent with the present observation for TBC1D4 $\mathrm{Thr}^{642}$ phosphorylation. In the present study, type 2 diabetic and obese non-diabetic individuals achieved an approximately $20 \%$ improvement in insulin-stimulated $R_{\mathrm{d}}$ in response to 10 weeks of exercise-training. Moreover, this increase in insulin sensitivity was accompanied by enhanced TBC1D4 phosphorylation at several sites. However, as seen in young, healthy individuals [11], these responses are partly attributable to the significant increase in TBC1D4 protein content. Nevertheless, even after correction for TBC1D4 protein content, training significantly increased insulinstimulated TBC1D4 phosphorylation at $\operatorname{Ser}^{588}$ and $\operatorname{Ser}^{751}$ in muscle of type 2 diabetic patients. These data suggest that the phosphorylation defects of TBC1D4 at $\mathrm{Ser}^{588}$ and $\mathrm{Ser}^{751}$ in skeletal muscle may be particularly sensitive to regular endurance training in type 2 diabetic patients and, as a consequence, may contribute to the improved insulin sensitivity in these individuals. In fact, these two sites are potently phosphorylated immediately post-exercise in muscle of young healthy males (J. T. Treebak, C. Pehmøller and J. F. P. Wojtaszewski, unpublished observations), as well as in a prolonged period into recovery from exercise [12]. While basal phosphorylation on these sites was unchanged by training, exercise by some unknown mechanisms seems to increase the sensitivity of these phosphorylation sites to insulin-mediated signals. Previously, activation of AMPK has been reported to enhance sensitivity of muscle glucose transport to insulin [45]. Moreover, AMPK preferentially phosphorylates TBC1D4 at $\mathrm{Ser}^{588}$ in vitro [6], which together with $\mathrm{Thr}^{642}$ seems to be the two major sites involved in GLUT4 translocation [4]. In agreement with these findings, we observed a significant increase in AMPK $\mathrm{Thr}^{172}$ phosphorylation in diabetic patients after training, which could explain the normalisation of insulin-stimulated TBC1D4 Ser ${ }^{588}$ phosphorylation. This increase in AMPK $\mathrm{Thr}^{172}$ phosphorylation was due to a more robust increase in AMPK protein levels in type 2 diabetic patients compared with controls.

An important finding in the present study was that 10 weeks of exercise-training abolished the defects in insulin-mediated TBC1D4 phosphorylation at $\mathrm{Ser}^{318}, \mathrm{Ser}^{588}$ and $\mathrm{Ser}^{751}$ in patients with type 2 diabetes, despite the fact that insulin-stimulated $R_{\mathrm{d}}$, although improved, remained lower than in matched control individuals after training, as reported earlier [31, 32, 46, 47]. This indicates that other factors beyond those regulating TBC1D4 phosphorylation at the sites measured in this study could explain the reduced insulin-stimulated $R_{\mathrm{d}}$ in type 2 diabetes after training. After the training period, defects in insulin action on Akt $\mathrm{Thr}^{308}$ phosphorylation and one of its major downstream effectors, glycogen synthase activity, persisted in muscle of type 2 diabetic patients. Thus, these factors are plausible candidates to explain the impaired insulin-stimulated $R_{\mathrm{d}}$, even in trained diabetic patients. Moreover, our data suggest the possibility that kinases other than Akt mediate the beneficial effect of exercise-training on TBC1D4 phosphorylation at $\operatorname{Ser}^{318}, \operatorname{Ser}^{588}$ and $\operatorname{Ser}^{751}$ [6]. Our data also question the strength of the relationship between traininginduced changes in Akt signalling and changes in insulin action on $R_{\mathrm{d}}$.

Based on previous reports, the beneficial adaptations to endurance training in skeletal muscle are mediated at least in part by increased protein content of molecules involved in glucose transport/uptake, including Akt1/2, TBC1D4, GLUT4, hexokinase II and different subunits of AMPK $[11,21,31-33,44]$. Although the modality and duration of training in these studies differed somewhat from those in the present study, our results provide further evidence that increased protein content of TBC1D4, Akt1 and Akt2, GLUT4, hexokinase II and AMPK in response to endurance training may be an important mechanism contributing to improved insulin-mediated glucose disposal in human skeletal muscle, even in insulin-resistant conditions such as obesity and type 2 diabetes. In fact, although GLUT4 is important for the glucose transport process, animal studies suggest that hexokinase II activity may represent a regulatory step for insulin-stimulated glucose uptake in skeletal muscle [48]. Thus with the marked reduction in pre-training hexokinase II protein levels being partially restored by training, similarly to changes observed for insulin-stimulated $R_{\mathrm{d}}$, this adaptation may be even more important in type 2 diabetic patients than in healthy individuals.

In most studies, improved insulin-stimulated glucose disposal after long-term endurance training can be attributed to increased glucose storage [31,32], thereby implicating a particular role for glycogen synthase. Consistent with another study of the effect of 8 weeks of training [32], we observed that endurance training increased total glycogen synthase activity, as well as glycogen synthase protein, in parallel with increased glycogen levels and improved insulin-stimulated $R_{\mathrm{d}}$ in skeletal muscle from obese non-diabetic and type 2 diabetic individuals. In contrast, the ability of insulin to stimulate glycogen synthase activity, as measured by the \% I-form or $\% \mathrm{FV}$, was unaffected by training in both groups. Similarly, no changes in glycogen synthase phosphorylation were seen after training when corrected for the increase in glycogen synthase protein. These findings demonstrate that training primarily increases protein content, rather than insulin-dependent dephosphorylation of glycogen synthase. Taken together, our data indicate that the molecular mechanisms by which exercise-training 
increases content of key signalling proteins mediating insulin-stimulated glucose metabolism in skeletal muscle are largely preserved in insulin-resistant obese individuals with and without type 2 diabetes. Further studies are warranted to identify the transcriptional and translational factors mediating these adaptations to aerobic training in skeletal muscle.

In summary, we found decreased insulin-stimulated TBC1D4 phosphorylation at $\mathrm{Ser}^{318}, \mathrm{Ser}^{588}$ and $\mathrm{Ser}^{751}$, in addition to previously reported defects at the level of Akt and glycogen synthase, in skeletal muscle from type 2 diabetic patients. Although the insulin-stimulated phosphorylation of $\mathrm{Ser}^{588}$ and $\mathrm{Ser}^{751}$ per TBC1D4 protein was significantly increased after endurance training in type 2 diabetic patients, other defects persisted, possibly explaining why insulin-stimulated $R_{\mathrm{d}}$ remained lower in type 2 diabetic patients. Nevertheless, insulin-stimulated $R_{\mathrm{d}}$ was significantly improved in response to training in obese nondiabetic individuals and in type 2 diabetic patients. Additional data indicate that this increase in insulin sensitivity may be achieved through improved signalling at the level of TBC1D4, as well as increments in protein levels of Akt1, Akt2, glycogen synthase, TBC1D4, GLUT4, hexokinase II and $\alpha 2$-AMPK.

Acknowledgements We acknowledge L. Hansen, C. B. Olsen and B. Bolmgren for skilled technical assistance. This study was supported by: the Institute of Clinical Research, University of Southern Denmark; the Danish Medical Research Council; the Novo Nordisk Research Foundation (including Excellence Project 2009); the Danish Diabetes Association; the Lundbeck Foundation; the European Research Council; and an Integrated Project (LSHM-CT-2004005272) funded by the European Commission. This work was carried out as part of the research programme of the UNIK: Food, Fitness \& Pharma for Health and Disease (www.foodfitnesspharma.ku.dk). The UNIK project is supported by the Danish Ministry of Science, Technology and Innovation. We thank G. D. Hardie (Division of Molecular Physiology, University of Dundee, Dundee, Scotland, UK) and O. Pedersen (Steno Diabetes Center, Gentofte, Denmark) for donating materials essential to this study.

Duality of interest The authors declare that there is no duality of interest associated with this manuscript.

\section{References}

1. Højlund K, Beck-Nielsen H (2006) Impaired glycogen synthase activity and mitochondrial dysfunction in skeletal muscle. Markers or mediators of insulin resistance in type 2 diabetes. Curr Diabetes Rev 2:375-395

2. Taniguchi CM, Emanuelli B, Kahn CR (2006) Critical nodes in signalling pathways: insights into insulin action. Nat Rev Mol Cell Biol 7:85-96

3. Kane S, Sano H, Liu SC et al (2002) A method to identify serine kinase substrates. Akt phosphorylates a novel adipocyte protein with a Rab GTPase-activating protein (GAP) domain. J Biol Chem 277:22115-22118
4. Sano H, Kane S, Sano E et al (2003) Insulin-stimulated phosphorylation of a Rab GTPase-activating protein regulates GLUT4 translocation. J Biol Chem 278:14599-14602

5. Kramer HF, Witczak CA, Taylor EB, Fujii N, Hirshman MF, Goodyear LJ (2006) AS160 regulates insulin- and contractionstimulated glucose uptake in mouse skeletal muscle. J Biol Chem 281:31478-31485

6. Geraghty KM, Chen S, Harthill JE et al (2007) Regulation of multisite phosphorylation and 14-3-3 binding of AS160 in response to IGF-1, EGF, PMA and AICAR. Biochem J 407:231-241

7. Treebak JT, Taylor EB, Witczak CA et al (2010) Identification of a novel phosphorylation site on TBC1D4 regulated by AMPactivated protein kinase in skeletal muscle. Am J Physiol Cell Physiol 298:C377-C385

8. Ramm G, Larance M, Guilhaus M, James DE (2006) A role for 14-3-3 in insulin-stimulated GLUT4 translocation through its interaction with the RabGAP AS160. J Biol Chem 281:2917429180

9. Cartee GD, Wojtaszewski JF (2007) Role of Akt substrate of $160 \mathrm{kDa}$ in insulin-stimulated and contraction-stimulated glucose transport. Appl Physiol Nutr Metab 32:557-566

10. Wojtaszewski JF, Richter EA (2006) Effects of acute exercise and training on insulin action and sensitivity: focus on molecular mechanisms in muscle. Essays Biochem 42:31-46

11. Frøsig C, Rose AJ, Treebak JT, Kiens B, Richter EA, Wojtaszewski JFP (2007) Effects of endurance exercise training on insulin signaling in human skeletal muscle: interactions at the level of phosphatidylinositol 3-kinase, Akt, and AS160. Diabetes 56:20932102

12. Treebak JT, Frosig C, Pehmoller C et al (2009) Potential role of TBC1D4 in enhanced post-exercise insulin action in human skeletal muscle. Diabetologia 52:891-900

13. Treebak JT, Birk JB, Rose AJ, Kiens B, Richter EA, Wojtaszewski JF (2007) AS160 phosphorylation is associated with activation of alpha2beta2gamma1- but not alpha2beta2gamma3-AMPK trimeric complex in skeletal muscle during exercise in humans. Am J Physiol Endocrinol Metab 292:E715-E722

14. Treebak JT, Wojtaszewski JF (2008) Role of 5'AMP-activated protein kinase in skeletal muscle. Int J Obes (Lond) 32(Suppl 4): S13-S17

15. Højlund K, Staehr P, Hansen BF et al (2003) Increased phosphorylation of skeletal muscle glycogen synthase at $\mathrm{NH} 2-$ terminal sites during physiological hyperinsulinemia in type 2 diabetes. Diabetes 52:1393-1402

16. Damsbo P, Vaag A, Hother-Nielsen O, Beck-Nielsen H (1991) Reduced glycogen synthase activity in skeletal muscle from obese patients with and without type 2 (non-insulin-dependent) diabetes mellitus. Diabetologia 34:239-245

17. Cusi K, Maezono K, Osman A et al (2000) Insulin resistance differentially affects the PI 3-kinase- and MAP kinase-mediated signaling in human muscle. J Clin Invest 105:311-320

18. Højlund K, Wojtaszewski JF, Birk J, Hansen BF, Vestergaard H, Beck-Nielsen H (2006) Partial rescue of in vivo insulin signalling in skeletal muscle by impaired insulin clearance in heterozygous carriers of a mutation in the insulin receptor gene. Diabetologia 49:1827-1837

19. Glintborg D, Højlund K, Andersen NR, Falck-Hansen B, BeckNielsen H, Wojtaszewski JFP (2008) Impaired insulin activation and dephosphorylation of glycogen synthase in skeletal muscle of women with polycystic ovary syndrome is reversed by pioglitazone treatment. J Clin Endocrinol Metab 93:3618-3626

20. Karlsson HK, Ahlsen M, Zierath JR, Wallberg-Henriksson H, Koistinen HA (2006) Insulin signaling and glucose transport in skeletal muscle from first-degree relatives of type 2 diabetic patients. Diabetes 55:1283-1288 
21. O'Gorman DJ, Karlsson HK, McQuaid S et al (2006) Exercise training increases insulin-stimulated glucose disposal and GLUT4 (SLC2A4) protein content in patients with type 2 diabetes. Diabetologia 49:2983-2992

22. Beeson M, Sajan MP, Dizon M et al (2003) Activation of protein kinase C-zeta by insulin and phosphatidylinositol-3, 4, 5-(PO4)3 is defective in muscle in type 2 diabetes and impaired glucose tolerance: amelioration by rosiglitazone and exercise. Diabetes 52:1926-1934

23. Bandyopadhyay GK, Yu JG, Ofrecio J, Olefsky JM (2005) Increased p85/55/50 expression and decreased phosphotidylinositol 3-kinase activity in insulin-resistant human skeletal muscle. Diabetes 54:2351-2359

24. Højlund K, Birk JB, Klein DK et al (2009) Dysregulation of glycogen synthase $\mathrm{COOH}$ - and $\mathrm{NH}_{2}$-terminal phosphorylation by insulin in obesity and type 2 diabetes mellitus. J Clin Endocrinol Metab 94:4547-4556

25. Karlsson HK, Zierath JR, Kane S, Krook A, Lienhard GE, Wallberg-Henriksson H (2005) Insulin-stimulated phosphorylation of the Akt substrate AS160 is impaired in skeletal muscle of type 2 diabetic subjects. Diabetes 54:1692-1697

26. Højlund K, Glintborg D, Andersen NR et al (2008) Impaired insulin-stimulated phosphorylation of Akt and AS160 in skeletal muscle of women with polycystic ovary syndrome is reversed by pioglitazone treatment. Diabetes 57:357-366

27. Adams JM II, Pratipanawatr T, Berria R et al (2004) Ceramide content is increased in skeletal muscle from obese insulin-resistant humans. Diabetes 53:25-31

28. Morino K, Petersen KF, Dufour S et al (2005) Reduced mitochondrial density and increased IRS-1 serine phosphorylation in muscle of insulin-resistant offspring of type 2 diabetic parents. $\mathrm{J}$ Clin Invest 115:3587-3593

29. Tuomilehto J, Lindstrom J, Eriksson JG et al (2001) Prevention of type 2 diabetes mellitus by changes in lifestyle among subjects with impaired glucose tolerance. N Engl J Med 344:1343-1350

30. Knowler WC, Barrett-Connor E, Fowler SE et al (2002) Reduction in the incidence of type 2 diabetes with lifestyle intervention or metformin. N Engl J Med 346:393-403

31. Wang Y, Simar D, Fiatarone Singh MA (2009) Adaptations to exercise training within skeletal muscle in adults with type 2 diabetes or impaired glucose tolerance: a systematic review. Diabetes Metab Res Rev 25:13-40

32. Christ-Roberts CY, Pratipanawatr T, Pratipanawatr W et al (2004) Exercise training increases glycogen synthase activity and GLUT4 expression but not insulin signaling in overweight nondiabetic and type 2 diabetic subjects. Metabolism 53:1233-1242

33. Daugaard JR, Richter EA (2001) Relationship between muscle fibre composition, glucose transporter protein 4 and exercise training: possible consequences in non-insulin-dependent diabetes mellitus. Acta Physiol Scand 171:267-276

34. Mogensen M, Vind BF, Højlund K, Beck-Nielsen H, Sahlin K (2009) Maximal lipid oxidation in patients with type 2 diabetes is normal and shows an adequate increase in response to aerobic training. Diabetes Obes Metab 11:874-883
35. Hey-Mogensen M, Højlund K, Vind BF et al (2009) Effect of physical training on mitochondrial respiration and reactive oxygen species release in skeletal muscle in patients with obesity and type 2 diabetes. Diabetologia 53:1976-1985

36. Birk JB, Wojtaszewski JF (2006) Predominant alpha2/beta2/ gamma3 AMPK activation during exercise in human skeletal muscle. J Physiol 577:1021-1032

37. Deshmukh A, Coffey VG, Zhong Z, Chibalin AV, Hawley JA, Zierath JR (2006) Exercise-induced phosphorylation of the novel akt substrates AS160 and filamin A in human skeletal muscle. Diabetes 55:1776-1782

38. Treebak JT, Glund S, Deshmukh A et al (2006) AMPK-mediated AS160 phosphorylation in skeletal muscle is dependent on AMPK catalytic and regulatory subunits. Diabetes 55:2051-2058

39. Plomgaard P, Bouzakri K, Krogh-Madsen R, Mittendorfer B, Zierath JR, Pedersen BK (2005) Tumor necrosis factor-alpha induces skeletal muscle insulin resistance in healthy human subjects via inhibition of Akt substrate 160 phosphorylation. Diabetes 54:2939-2945

40. Taylor EB, An D, Kramer HF et al (2008) Discovery of TBC1D1 as an insulin-, AICAR-, and contraction-stimulated signaling nexus in mouse skeletal muscle. J Biol Chem 283:9787-9796

41. Pehmøller C, Treebak JT, Birk JB et al (2009) Genetic disruption of AMPK signaling abolishes both contraction- and insulinstimulated TBC1D1 phosphorylation and 14-3-3 binding in mouse skeletal muscle. Am J Physiol Endocrinol Metab 297: E665-E675

42. Krook A, Roth RA, Jiang XJ, Zierath JR, Wallberg-Henriksson H (1998) Insulin-stimulated Akt kinase activity is reduced in skeletal muscle from NIDDM subjects. Diabetes 47:1281-1286

43. Højlund K, Frystyk J, Levin K, Flyvbjerg A, Wojtaszewski JFP, Beck-Nielsen H (2006) Reduced plasma adiponectin concentrations may contribute to impaired insulin activation of glycogen synthase in skeletal muscle of patients with type 2 diabetes. Diabetologia 49:1283-1291

44. Vestergaard H, Bjørbaek C, Hansen T, Larsen FS, Granner DK, Pedersen O (1995) Impaired activity and gene expression of hexokinase II in muscle from non-insulin-dependent diabetes mellitus patients. J Clin Invest 96:2639-2645

45. Fisher JS, Gao J, Han DH, Holloszy JO, Nolte LA (2002) Activation of AMP kinase enhances sensitivity of muscle glucose transport to insulin. Am J Physiol Endocrinol Metab 282:E18E23

46. Dela F, Larsen JJ, Mikines KJ, Ploug T, Petersen LN, Galbo H (1995) Insulin-stimulated muscle glucose clearance in patients with NIDDM. Effects of one-legged physical training. Diabetes 44:1010-1020

47. Bruce CR, Kriketos AD, Cooney GJ, Hawley JA (2004) Disassociation of muscle triglyceride content and insulin sensitivity after exercise training in patients with type 2 diabetes. Diabetologia 47:23-30

48. Wasserman DH (2009) Four grams of glucose. Am J Physiol Endocrinol Metab 296:E11-E21 